\title{
FUTURE AIRPORTS DEVELOPMENT STRATEGIES
}

Air transport was traditionally highly regulated, fragmented and protected. With European air transport market deregulation in the mid 1980s also airports could respond to new factors. Methodology developed within the FAST project analyzed evolution of airport strategies potential in the forthcoming decade in the frame of new airport typology reflecting different strategies depending on the airport size, market type and market potential.

Keywords: Airport development, airport strategies, deregulation.

\section{Background}

The last decade in the European air transport market was characterized by air transport deregulation which resulted in the appearance and growth of the low cost airlines segment which characterizes a prominent share of intra-European market today [1]. Another significant advancement was the change in the airports management. Many airports transformed from public to private ownership. In the new environment airports could play a more active role in the air transport industry. They improved their attractiveness and competitiveness [2], [3], [4]. Many of secondary airports have developed more active strategies towards airlines and, in particular, toward low cost carriers.

Airlines' strategies are those more explored. However, airport strategies and their future development are one of the main drivers of traffic evolution [5]. The airports are no passive players and their strategies have significant impact on airline behavior and route structure. This paper describes new trends in airport strategies and how they are adopted by airports.

The paper analyzes potential progress of airport strategies and provides some answers to questions relating to stakeholders and clients (airlines and passengers) needs. However, there are no universal strategies feasible for any airport but it depends on the airport characteristics. [6] This reality led us to build an innovative typology of airports aimed at three elements: airport size, potential for growth in capacity and potential in demand.

Long term traffic forecasts are stable and promising for the air transport sector [6]. The principle question at the airport level is the capability to receive increasing number of passengers in the future, i.e. its capacity to grow. This element will characterize the possible evolution/adaptation of recourses to a general increase of demand. The role of the third element, airport actual size, is to take into account the existing situation of an airport. This allows us to reflect the past strategies of a given airport.

Based on this typology and the generic strategies defined we outlined the future strategies available to a given airport.

This methodology was developed within the FAST project funded by EUROCONTROL in 2008-2009. The results [7], [8], [9] were illustrated by an application to Bordeaux airport in France. After the end of this project, it is interesting to observe and compare the strategy developed by the airport, with the analysis made in the FAST project.

\section{Methodology}

\subsection{Airport strategies}

\subsubsection{Airport customers and revenues}

Airports are typical service organizations [10]. From the aeronautical perspective, the main airport clients are airlines of all types: traditional airlines, low cost carriers, but also cargo/freight airlines and integrators. Airports provide them with infrastructure (e.g. runways, taxiways, aprons, terminals) and services (e.g. refueling and handling). Services can be provided directly by the airport, or subcontracted to private companies. Passengers are considered to be especially airline clients but they are also direct clients of airports as they must be processed before/after their flight. The range of non-aeronautical services depends on the airport size and type and they usually include shops, restaurants and bars providing services to the passengers, visitors and employees and bringing revenues to the airport. Needs and wants of airport customers can be conflicting: for example, passengers prefer short connections times

\footnotetext{
* Antonin Kazda ${ }^{1}$, Benedikt Badanik ${ }^{1}$, Anna Tomova ${ }^{1}$, Isabelle Laplace ${ }^{2}$, Nathalie Lenoir ${ }^{3}$

${ }^{1}$ Faculty of Operation and Economics of Transport and Communications, University of Zilina, Slovakia, E-mail: antonin.kazda@fpedas.uniza.sk

${ }^{2}$ M3 Systems; 26 rue du Soleil Levant, Lavernose, France

${ }^{3}$ Estelle Malavolti - L'Ecole Nationale de l'Aviation Civile (ENAC), Toulouse, France
} 
between flights, while shop keepers would prefer passenger long dwell times in the terminal to increase their sales potential.

The revenues of an airport are usually split into aeronautica revenues and non-aeronautical revenues [11]. The aeronautical revenues are linked with the aeronautical activities of passengers and aircraft, and the non-aeronautical revenues are all other revenues. However, these can be further split into two groups: revenues from service providers located at an airport, providing services either to the airlines or to the passengers; and revenues from activities the airport has diversified in order to use its expertise [12] Those could be for example consultancy or management services. The strategies of specialization will aim at developing the aeronautical revenues, whereas the strategies of diversification will have the objective of increasing the non-aeronautical revenues.

\subsubsection{Strategies of specialization}

Strategies of specialization are focused to develop airport aeronautical activities. Some could be related to aeronautical infrastructure, while others will aim to increase service levels, or improve the communication or marketing towards clients [13].

Concerning the airport infrastructure, examples are:

- Increase of the runway capacity by extending the existing runway and/or building a new runway and/or other investments in the airport movement areas (for example taxiways system completion, apron expansion).

- Investment in passenger terminal capacity by building a new terminal, extending existing ones or processing technology improvements.

- Investment in freight terminal capacity by improving technology, building a new terminal or extending existing ones.

- Investment in a low-cost terminal to enable differentiation of the airport service level quality.

Strategies of specialization centered on quality improvement can include:

- Improvement of airport accessibility via bus shuttles, car parking, road and/or rail infrastructure (which often requires financial support from the region, town, etc.).

- Investment in terminal infrastructure to improve the efficiency of aeronautical services (e.g. luggage transfer and passengers flows).

- Development of intermodality with a high-speed rail interconnection (which requires financial support from the country, region, town, etc.).

Finally, policies towards customer could include:

- Development of commercial policies to airlines (e.g. lower passenger taxes to airline opening new lines, reaching a certain level of traffic at the airport, lower taxes on subsidized routes and lower taxes for transit passengers).

- Investment in publicity, communication and marketing towards airlines (market research, advertisement) or towards passengers (advertising the region's attractiveness, ...).

\subsubsection{Strategies of diversification}

A diversification strategy of a company consists in developing activities not related to the core businesses. This strategy can result in reduction of a firm's exposure to a risk. Indeed, if its core business is affected by a crisis, the company can still generate profits through different strategy. For airports, strategies of diversification aim to develop the non-aeronautical activities. They are considered increasingly important to stabilize and balance the airport economy.

These diversification strategies mainly aim at:

- Improving the financial results by increasing non-aeronautical revenues with the development of commercial activities.

- Diversifying the financial risks by investing in other airports or other economic sectors.

- Finding a way to allocate the airport's capital elsewhere than in the airport capacity when the potential of capacity growth of the airport is low.

- Offices or land rental.

The most common diversification strategy is the development of commercial activities by increasing the areas for shops, restaurants, car rentals, etc., at the airport. The strategy of diversification concerns the development of services to the airport passenger independently of the airlines (lounges, wireless internet, trip planner websites...) [14]. The objective is to increase revenues and to indemnify the loyalty of passengers toward airports. This type of strategy improves revenues, but does not reduce the risk exposure, as the revenues are still closely linked to the number of passengers attracted by the airlines. In case of a traffic decrease, these revenues will also be impacted. These strategies are applicable to any airport, even small ones. Other strategies of diversification of midsize or large airports consist in selling the airport know-how to other airports by developing consultancy or management services. Airports can also invest in other airports or other economic sectors. [15] These last strategies of diversification however require financial resources and are therefore generally developed only by large airports.

\subsection{Typology of airports}

The strategies available to a particular airport depend on its characteristics not only in terms of current traffic, but also considering the airport potential with respect to capacity and demand [16], [17], [18]. The current situation of an airport in terms of passenger throughput or cargo volume is not necessarily the best indicator of what the airport could become in 10 or 20 years. Some airports have grown massively in the past 10 years while others have not. Analyzing the future evolutions of airport strategies therefore requires us to confront the information on the airport traffic forecasts with other elements.

We are interested in identifying the characteristics of an airport in terms of its potential: what can explain why a given airport will develop, while another will not? We are looking at airports from 
the point of view of traffic evolution. To be able to grow, an airport needs to have 'good characteristics' in terms of supply (mainly capacity) and demand.

\subsubsection{Airport capacity}

For a midsize or large airport the most important parameter is always the runway capacity which limits the traffic volume in peaks. This should be linked with apron capacity, the passenger or freight terminal capacity, but also airport surface access infrastructure in case of large airports. Indicators of the airport potential for growth in capacity relate to the current runway system, apron and terminal capacity but also to their possibility of future extension.

\subsubsection{Airport demand}

In order to grow, an airport should have spare capacity, to accommodate more flights and/or more passengers or cargo, but it would be of no benefit if there is no demand. Indicators of the potential for growth of the airport in terms of demand are based on passenger numbers on incoming/outgoing segments of the market. Some airports have mostly incoming passengers, leisure or business, because of some attractiveness of the area. Others have mostly outgoing passengers and this has to do with different factors, linked to population wealth in the region (depending on an adequate supply of flights at the airport). Some airports are hubs and have an important proportion of connecting passengers for whom the region around the airport will be unimportant. Last, cargo demand will have different requirements. Overall indicators of the potential for growth in demand relate mainly to intrinsic characteristics of the airport region [19].

\subsubsection{Airport typology}

All indicators of the airport potential for growth in capacity and demand can then be used to develop a typology of airports that will be used as a basis for the FAST project. In addition to the potential for growth in capacity and demand the analysis of the possible strategies takes into consideration the airport size according to the ACI airport size typology:

- Small size for airports with no more than 5 million passengers a year.

- Medium size for airports with more than 5 million passengers a year and fewer than 10 million passengers a year.

- Large size for airports with more than 10 million passengers a year.

Our typology of airports is therefore based on three parameters: the airport size determined by number of passengers, the level of potential for growth in capacity and the level of potential for growth in demand. Both levels of potential for growth are decomposed into low, medium and high potential levels. Fig. 1 illustrates this three dimensional typology with examples of airports.

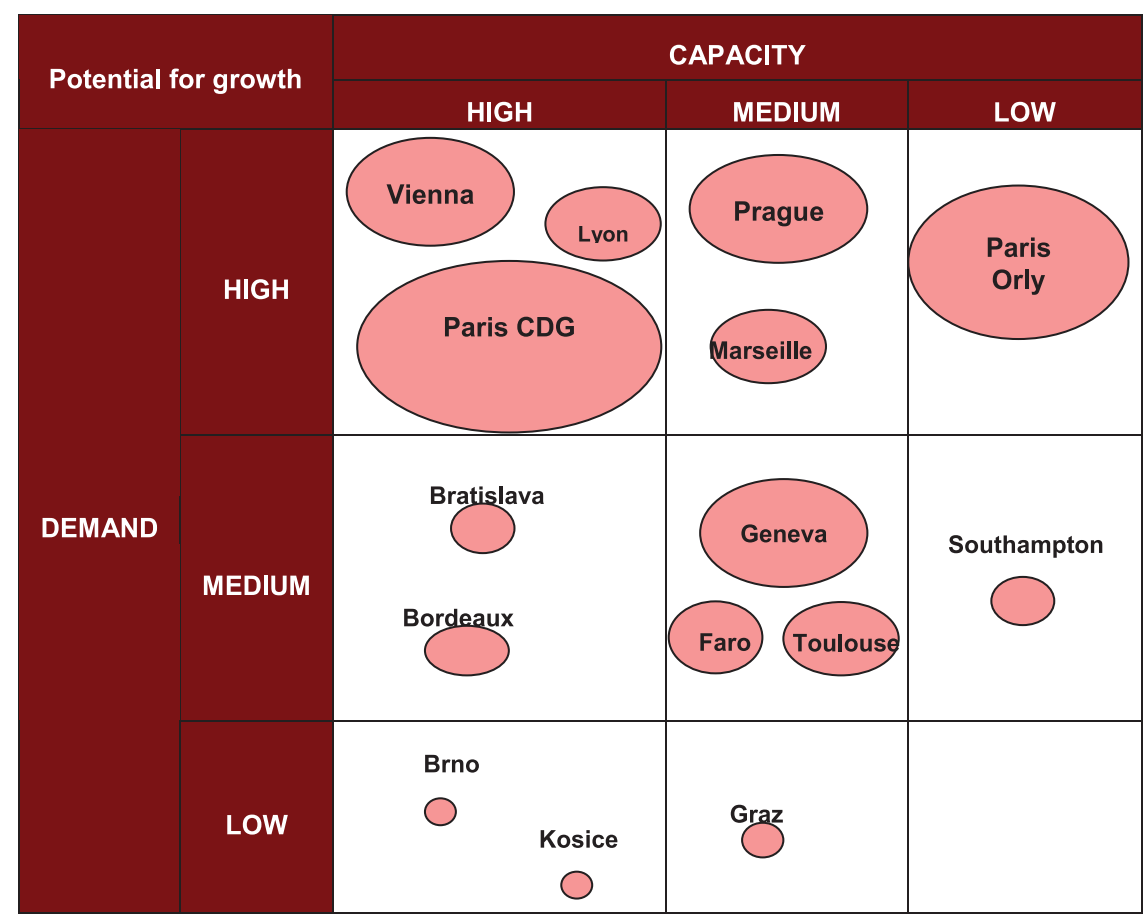

\section{Legend}

1 million pax

0

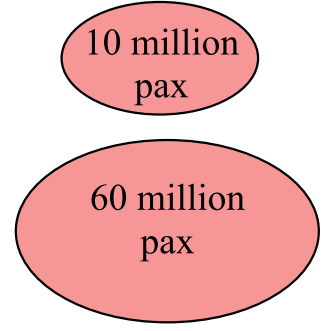

Fig. 1 Illustration of the three dimensional airport typology Source: FAST project, EUROCONTROL CARE INO project, March 2009 


\section{Strategic alternatives and future network}

\subsection{Method of identification of strategic alternatives}

To identify the strategic alternatives for a particular airport and to make predictions about its future route network evolution can be broken down as follows:

- Analyses of the past strategies of the considered airport.

- Identification of the future strategic alternatives of the analyzed airport according to its position in our typology of airports.

- Identification of a reference airport which has developed past strategies similar to the future strategies of the considered airport.

- Analysis of the past route network evolution of the reference airport following the strategy it developed.

- Use of this past route network evolution of the reference airport to make predictions about the future route network evolution of the analyzed airport.

\subsubsection{Past strategies}

The future strategic alternatives of an airport are closely related to the strategies it developed in the past. These past strategies were influenced by the airport characteristics and environment. It is therefore essential to analyze the past strategies of an airport before being able to identify its future strategic options.

\subsubsection{Future strategies by airport type}

The future strategies that can be developed by an airport will first be significantly dependent on its type. As an example, a medium sized airport with spare capacity will not behave in the same way as a large airport with runway capacity constraints [20]. The situation in terms of demand will also condition the type of passengers the airport plans to attract (local or foreign? business or tourists?) but also airline type (traditional or low cost) (see Fig. 2) [21], [22], [23]. Besides the type of the airport the degree of development of these strategies will be strongly linked to the level of competition with other airports, the level of congestion of the airport but also to the airport ownership and management and the limits of regulation of the airport [24], [4], [25].

Our method of identification of the possible strategies of an airport therefore comprises three steps: We first identify all the possible strategies of specialization for particular type of airport, then all the possible strategies of diversification. Finally, we refine these strategic options (specialization and diversification strategies) with other factors: capacity constraints, competition level, regulation type, airport status. As a result, we identify the airport objectives and strategic options at a five to eight year time horizons.

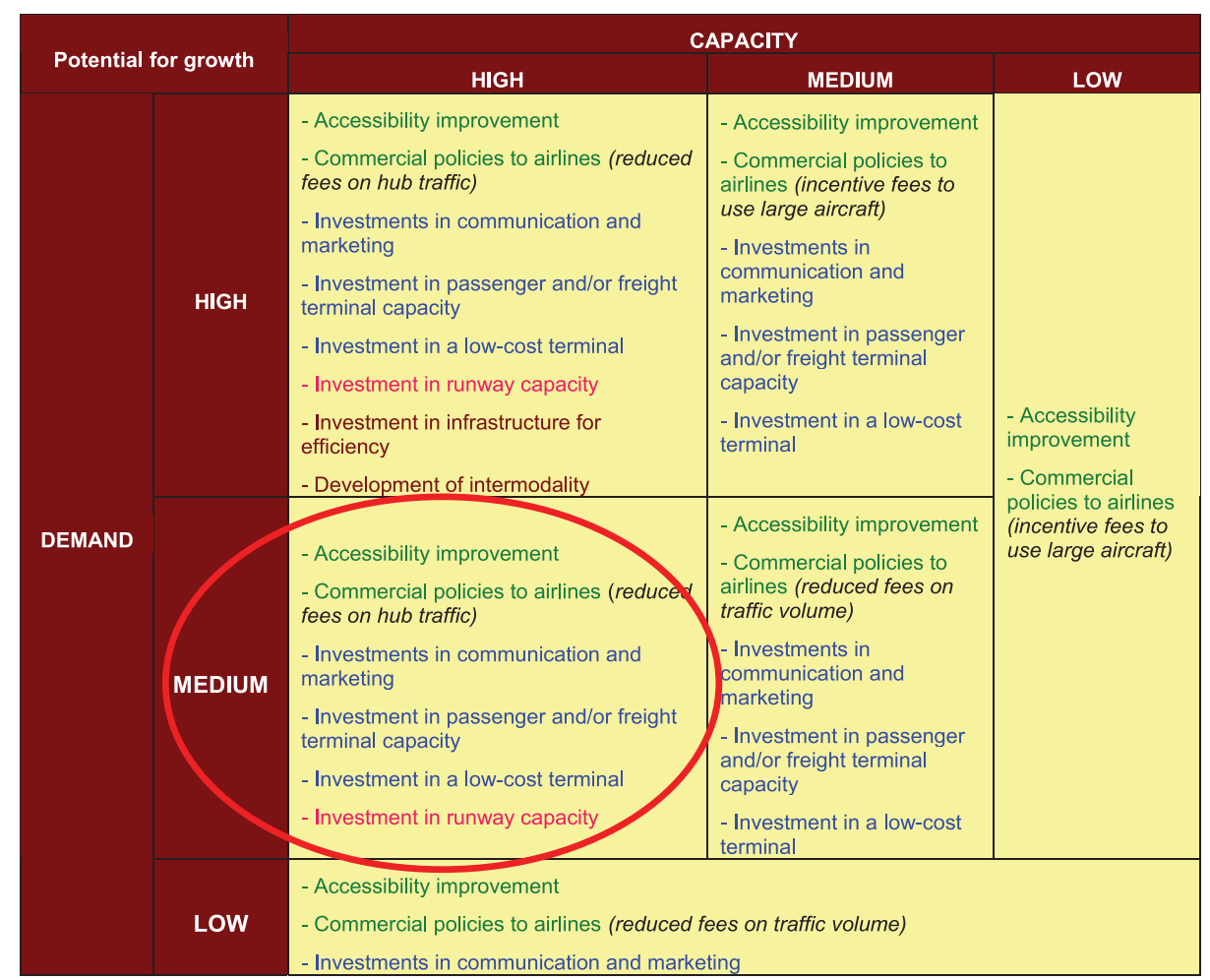

Fig. 2 Strategies of specialization by airport type

Source: FAST project, EUROCONTROL CARE INO project, March 2009 


\section{Conclusion}

Airports are essential actors in the air transport market with a growing role, market stabilizing effect and independence in strategic decision-making. Analyzing the impact of future airport strategies on the evolution of the airport route structure is significant and could give important clues as to the direction of future development of the industry.

This paper describes some aspects of the FAST project, which developed a new methodology for identification of the future airport strategies that can be applied to any European airport. In particular, we demonstrated that while strategies of diversification are often considered the preserve of large firms, they have been successfully applied by (and should be considered by) rather small airports to stabilize their economy in the years of crises.

The future airport strategies should also put more stress on avoiding so called 'curb-to-curb' approach. Airports should be viewed as integral part of the regional, national or international transport infrastructure rather than being perceived as an isolated transportation system. Quality of airport ground access/egress and level of airport integration into ground transport network significantly influences its competitiveness, operations and capacity.

The study researched few airports only. The methodology could be extended and refined by including more detailed parameters and could be extended to all airport types. Airports in the new European member states could give us different strategic options, but also to airports with overlapping catchment areas as well as to the competing hubs, low cost 'pseudo hubs' or complementary airports in case of multi-airport systems and/or complementarity between hub and secondary airports could be researched.

The relevance of the results of our methodology was confirmed by the Bordeaux airport strategy. In June 2009, three months after the end of the FAST project, Bordeaux Merignac airport decided to build a low-cost terminal of $4,000 \mathrm{~m}^{2}$ which opened in May 2010 . This strategy was fully in line with the results we obtained for Bordeaux airport: attracting additional low-cost and securing the loyalty of passengers in expectation of strong future competition with the high-speed train in 2016.

Three years after the opening of the Billi, the low-cost terminal, this strategy reveals successful since the airport traffic already increased by 1 million passengers since 2010, while the impact of the high-speed train competition in 2016 is expected to reduce the airport traffic by 800,000 passengers.

To reach the final objective of getting one additional million passengers by 2016 , the airport plan to enlarge by $2,000 \mathrm{~m}^{2}$ the Billi terminal from 2013

\section{References}

[1] WALKER, W., MARCHAU, V.: Low-cost Airports for Low-cost Airlines: Flexible Design to Manage the Risks. Paper Prepared for Special Issue of Journal of Transportation Planning and Technology, editors, Richard de Neufville, Massachusetts Institute of Technology, Cambridge, 2007.

[2] European Commission: Study on Competition between Airports and the Application of State Aid Rules. Final report Volumes 1 and 2, Directorate General Energy and Transport, Directorate F - Air transport; 2002.

[3] GRAHAM, A.: Airport Strategies to Gain Competitive Advantage. University of Westminster, GARS: Slots, Airport Competition and Benchmarking of Airports, Bremen, November 2004

[4] STARKIE, D.: Airport Regulation and Competition. J. of Air Transport Management, No. 2, 2002.

[5] Conseil National des Transports; Dossier N ${ }^{\circ}$ : Les Strategies Aeroportuaires en Europe. Observatoire National des Transports, March 2007.

[6] DE NEUFVILLE, R.: Management of Multi-airport Systems: A Development Strategy. J. of Air Transport Management, vol. 2, No. 2, June 1995, pp. 99-110.

[7] M3 Systems, ENAC, University of Zilina: WP1: Actual Air Transport Situation and Market Environment. FAST project, EUROCONTROL CARE INO project, June 2008.

[8] M3 Systems, ENAC, University of Zilina: WP2: Airport Strategic Options and Future Tendencies. FAST project, EUROCONTROL CARE INO project, December 2008.

[9] M3 Systems, ENAC, University of Zilina: WP3: Impacts of Airport Strategies on Traffic Distribution. FAST project, EUROCONTROL CARE INO project, March 2009.

[10] GILLEN, D., NIEMEIER, H.-S.: Airport Economics, Policy and Management: The European Union. Rafael del Pino Foundation, Comparative Political Economy and Infrastructure Performance: The case of airports, Madrid, September 2006.

[11] EUROPEAN COMMISSION: Directive of the European Parliament and of the Council on Airport Charges. COM(2006) 820 final; 2007.

[12] IATA: Economic regulation. IATA Publishing; 2007.

[13] RIES, A., TROUT, J.: Marketing Warfare. ISBN 0-07-052730-X; McGraw-Hill, 1986.

[14] STARKIE, D. YARROW, G.: The Single-till Approach to the Price Regulation of Airports. Civil Aviation Authority, London, 2002 


\section{COMMNICOIIIONS}

[15] TRETHEWAY, M.: Airport Ownership, Management and Price Regulation. InterVISTAS Consulting Inc. Research conducted for the Canada Transportation Act Review, March 2001.

[16] BARRETT, D.: How do the Demands for Airport Services Differ between Full-service Carriers and Low-cost Carriers? J. of Air Transport Management, 10, 33-39, 2004.

[17] CAA: Recent Trends in Growth of UK Air Passenger Demand, January 2008.

[18] STEFANIK, M.: Problems of Airport Capacity Assessment, Doctoral thesis, University of Zilina, Slovakia, 2009.

[19] DGAC : L'utilisation du transport aerien, Enquete sur le taux de penetration du transport aerien en France. Direction des Affaires Strategiques et Techniques, July 2007.

[20] DENNIS, N.: Long-term Route Traffic Forecasts and Fight Schedule Pattern for a Medium-sized European Airport. J. of Air Transport Management, 8, 313-324, 2002.

[21] CAA: No Frills Carriers: Revolution or Evolution? A study by the Civil Aviation Authority. CAP 770, November 2006.

[22] CAA: CAA Passenger survey report 2006. Economic regulation Group, Survey of passengers at Belfast City, Belfast International, Birmingham, Gatwick, Heathrow, London City, Londonderry, Luton, Manchester, Nottingham East Midlands \& Stansted, 2007

[23] CCI Marseille Provence ; Profils des voyageurs et nouveautes S08. Chambre de Commerce et d'Industrie Marseille Provence, 2008, www.marseille-aeroport.fr; retrieved 15. 6. 2009

[24] FORSYTH, P., GILLEN, D., KNOR, A., MAYER, O.G., NIEMEIER, H.: The Economic Regulation of Airports. Ashgate, 2004

[25] EUROCONTROL: Challenges of Growth 2008. Summary Report, Eurocontrol, STAFOR, November 2008. 